\title{
Obscure gastrointestinal haemorrhage of small-bowel origin
}

\author{
J N THOMPSON, A P HEMINGWAY, G A D McPHERSON, H C REES, D J ALLISON, J SPENCER
}

\begin{abstract}
The records of 37 patients investigated for obscure gastrointestinal haemorrhage originating from the small bowel were reviewed retrospectively. Bleeding was caused by Meckel's diverticula in eight cases, smooth muscle tumours in seven cases, vascular anomalies in 14 cases, and other single lesions in eight cases. The lesions were identified by angiography in 18 patients, operation in 17, and barium follow through examination in two. Only one patient under 50 years of age had a lesion that would not have been found by careful laparotomy.

Early laparotomy is advisable in patients aged under 50 with obscure gastrointestinal bleeding; expert selective angiography is recommended before operation in patients aged over 50 and those who have already undergone a laparotomy yielding negative results.
\end{abstract}

\section{Introduction}

Gastrointestinal haemorrhage is termed obscure when its cause remains unknown after standard radiological or endoscopic investigation, or both, of the upper and lower gastrointestinal tract. In roughly $5 \%$ of all patients presenting with gastrointestinal haemorrhage the cause is obscure. ${ }^{1}$ Most of these patients probably have colonic angiodysplasia. ${ }^{2}$ The small bowel is a less common source of haemorrhage. We reviewed retro-

\footnotetext{
Hammersmith Hospital and Royal Postgraduate Medical School, London W12 0HS

J N THOMPSON, MA, FRCS, surgical registrar

A P HEMINGWAY, MRCP, FRCR, senior lecturer, department of radiology G A D MCPHERSON, MA, FRCS, surgical senior registrar

H C REES, MB, FRCPA, histopathology registrar

D J ALLISON, MD, FRCR, professor and director, department of radiology J SPENCER, MS, FRCS, senior lecturer, department of surgery

Correspondence to: $\mathrm{Mr} \mathrm{J}$ Spencer.
}

spectively the records of 37 patients who had presented with obscure gastrointestinal bleeding and in whom a cause was subsequently found in the small bowel to determine the initial method of diagnosis and assess the relative values of small-bowel contrast studies, selective visceral angiography, and diagnostic laparotomy.

\section{Patients and methods}

We reviewed retrospectively the records of 37 patients who had been investigated at this hospital during 1975-83 for obscure gastrointestinal bleeding that was subsequently found to be associated with abnormalities of the small bowel. Four of the patients came from the local district (one emergency, three routine) and 33 were referred from other hospitals (three urgent transfers, 30 for elective investigation). Twenty seven patients presented with melaena, eight with recurrent anaemia, one with haematemesis, and one with bleeding via an ileostomy. Ten patients had undergone surgery previously for bleeding (one operation, seven patients; two operations, two patients; and three operations, one patient). Twenty one patients underwent radiological contrast studies of the small bowel (two undergoing only enema of the small bowel), 35 selective visceral angiography, and 34 surgery.

The Wilcoxon and Fisher tests were used for statistical analysis.

\section{Results}

DIAGNOSIS

Four general causes of gastrointestinal bleeding were identifiednamely, Meckel's diverticula, smooth muscle tumours, vascular anomalies, and other disorders. Table I gives the procedure that initially identified these causes. Table II gives the clinical details of the 37 patients grouped according to the cause of the bleeding.

In addition to showing 18 lesions of the small bowel (table I) angiography showed eight cases of caecal angiodysplasia, of which four were associated with Meckel's diverticula, two with jejunal vascular anomalies, one with an ulcerated duodenal diverticulum, and one with a solitary ulcer of the jejunum.

Most diagnostic problems that arose during operation were in the patients with vascular anomalies. In six of the seven in whom 
TABLE I-Numbers of patients in whom particular types of lesions were found by particular methods. Figures in parentheses indicate numbers of patients in whom each procedure was done

\begin{tabular}{lcccc}
\hline & $\begin{array}{c}\text { Barium } \\
\text { follow through }\end{array}$ & Angiography & Surgery & Total \\
\hline Meckel's diverticula & $1(4)$ & $0^{*}(6)$ & $7(8)$ & 8 \\
Smooth muscle tumours & $0(6)$ & $6(7)$ & $1(7)$ & 7 \\
Vascular anomalies & $0(6)$ & $7(14)$ & $7(13)$ & 14 \\
Other disorders & $1(3)$ & $5(8)$ & $2(6)$ & 8 \\
\hline Total & $2(19)$ & $18+(35)$ & $17(34)$ & 37 \\
\hline
\end{tabular}

* Meckel's diverticula suggested on basis of anomalous artery in two patients.

+ Four $(11 \%)$ of the 35 had active bleeding at time of angiography.

angiography had shown an abnormality radiological help was required in the operating theatre to localise the lesion. In five of the seven in whom preoperative angiography had not shown an abnormality vascular anomalies were identified at operation as macroscopic lesions varying from large palpable "tumours" to multiple small (1-2 $\mathrm{mm}$ ) vascular lesions. In the remaining two patients yielding negative results to preoperative angiography peroperative endoscopy of the small bowel was needed to identify vascular anomalies.

Technetium- $99 \mathrm{~m}$ pertechnetate scanning was done in five of the eight patients with Meckel's diverticula, four of whom were later found to have ulcerated diverticula with histological evidence of ectopic gastric mucosa. In three of these patients scanning had been done before referral to this hospital, and all five of the scans showed negative results.

Scanning with red cells and sulphur colloid labelled with $99 \mathrm{~m}$ Tc was done in seven patients, three of whom had rebled from vascular anomalies of the small bowel. In two haemorrhage from the jejunum was identified and in another two the rate of bleeding was measured. Of the 10 patients who had previously undergone operation for bleeding, eight were found to have vascular anomalies (five identified at angiography, three at operation), one an ulcerated duodenal diverticulum (identified at operation), and one a jejunal leiomyoma (identified at angiography). Only one of the 15 patients aged under 50 had a lesion that could not be identified at operation without the aid of localisation by angiography or endoscopy of the small bowel whereas seven of the 19 patients aged 50 or more had such lesions $(p=0.09)$.

\section{PATHOLOGICAL FINDINGS}

Six of the eight Meckel's diverticula showed peptic ulceration, and in five of these six ectopic gastric mucosa was confirmed microscopically. One Meckel's diverticulum did not show any ulceration or ectopic gastric mucosa, and another showed ectopic gastric mucosa but no ulceration. In six patients with smooth muscle tumours the tumours appeared to be histologically benign; in the seventh the tumour was considered to be potentially malignant. In six the tumours were in the proximal jejunum; and in the seventh it was in the second part of duodenum. In 13 patients with vascular anomalies these anomalies were resected. Ten were jejunal, two ileal, and one duodenal. In seven cases vascular lesions were shown histologically (three arteriovenous malformations, two cavernous haemangiomas, one multiple phlebectasia, and one telangiectasia). In one further case probable angiodysplasia of the small bowel was shown by microangiography. In the remaining five cases specimens of the small bowel did not show vascular abnormality; three of these patients had vascular lesions that were not seen at operation but were resected after angiographic localisation, and two had multiple small vascular lesions (2-3 $\mathrm{mm}$ diameter) in the jejunum.

The eight "other causes" of gastrointestinal bleeding were a duodenal reduplication, an ulcerated duodenal diverticulum, an ulcerated jejunal diverticulum, secondary angiosarcomatous deposits, a solitary jejunal ulcer, multiple ischaemic ulcers of the small bowel, and an ulcerated ileal lymphoma. One case of small-bowel haemorrhage was associated with chronic granulocytic leukaemia.

\section{TREATMENT AND FOLLOW UP}

A patient with telangiectasia affecting the small bowel and another with leukaemia and angiographic evidence of small-bowel haemorrhage were treated conservatively. A third patient who was seriously ill with concurrent pulmonary and cardiac problems died without undergoing surgery; multiple ischaemic ulcers of the small bowel were confirmed post mortem. The 34 other patients underwent surgical resection or excision of their small-bowel lesions. The patient with a solitary smallbowel ulcer and angiodysplasia of the caecum underwent resection of both lesions at one operation. The postoperative complications recorded were one pulmonary embolus, one jejunal fistula (managed conservatively), one wound infection, and one early incisional hernia. There were no postoperative deaths. No complications developed after angiography.

The follow up data were incomplete for several patients, largely because of the pattern of referral. The median duration of follow up was 10 months (range 1-79). Six patients bled again after a median of five months (range 2 weeks to 16 months). Two underwent further resections of the small bowel for additional vascular lesions. Two in whom no histological lesion had been found had vascular anomalies; one, who had had macroscopic jejunal lesions previously, underwent right hemicolectomy for angiodysplasia of the caecum, and the other, who had undergone a previous resection of a jejunal lesion under radiological guidance, was later lost to follow up. The fifth patient who rebled, a woman with leukaemia affecting the small bowel, was treated conservatively. The remaining patient who rebled had an ulcerated duodenal diverticulum.

\section{Discussion}

In patients with obscure gastrointestinal haemorrhage it is important to be certain that common causes in the oesophagus, stomach, duodenum, and colon have been excluded, ${ }^{3}$ and this partly explains the number of previous gastrointestinal investigations that had been performed in our patients. Angiodysplasia of the colon is probably the commonest cause of obscure gastrointestinal bleeding, ${ }^{2}$ and, though it may be congenital in origin, ${ }^{4}$ it is rarely symptomatic until old age. ${ }^{5}$ Haemobilia, pancreatic disease, vasculitis, inherited connective tissue disorders, aortoenteric fistula, and nasopharyngeal bleeding must all be considered in addition to small-bowel lesions as alternative causes of haemorrhage.

The patients in this series were difficult to manage and comprised a highly selected group, most of whom were referred for selective visceral angiography after investigations at other hospitals yielded negative results.

Angiography identified the lesion in $51 \%$ of the patients in whom it was done and proved invaluable in six of the patients with vascular anomalies that could not be identified at operation without radiological help. In these patients, various techniques previously described were used and found to be of value, including peroperative angiography and the use of methylene blue injected via a selectively positioned arterial catheter. ${ }^{6-8}$ The presence of colonic angiodysplasia in patients with Meckel's diverticula has been reported previously. ${ }^{9}$ The association of eight small-bowel lesions with caecal angiodysplasia in this series emphasises the importance of thorough laparotomy in patients with a preoperative diagnosis of colonic angiodysplasia.

Although operation has recently been said to be of little value in the diagnosis of obscure gastrointestinal bleeding, ${ }^{3}$ it played an important part in diagnosis as well as treatment in our patients. Lesions were not identified until operation in 17 patients $(46 \%)$, and all but two of these had undergone previous selective angiography. Half of the vascular anomalies were not shown by angiography and were identified only at operation. These were predominantly venous lesions, which are difficult to show radiologically. Though the value of careful inspection and palpation of the small bowel has been doubted, ${ }^{6}$ we found this technique to be diagnostic on several occasions. Transillumination and "stripping" of the small bowel through the fingers throughout its length, usually repeated at least once, showed small lesions that would otherwise have been easily missed.

Although some preselection probably occurred, the failure of ${ }^{99 \mathrm{~m}} \mathrm{Tc}$ pertechnetate scanning to identify any of the four Meckel's diverticula with ectopic gastric mucosa in the patients in whom it was done shows further the insensitivity of this technique. ${ }^{10}$ The use of cimetidine or pentagastrin may reduce the incidence of false negative results. ${ }^{11} 1299 \mathrm{~m} T \mathrm{Tc}$ sulphur colloid 


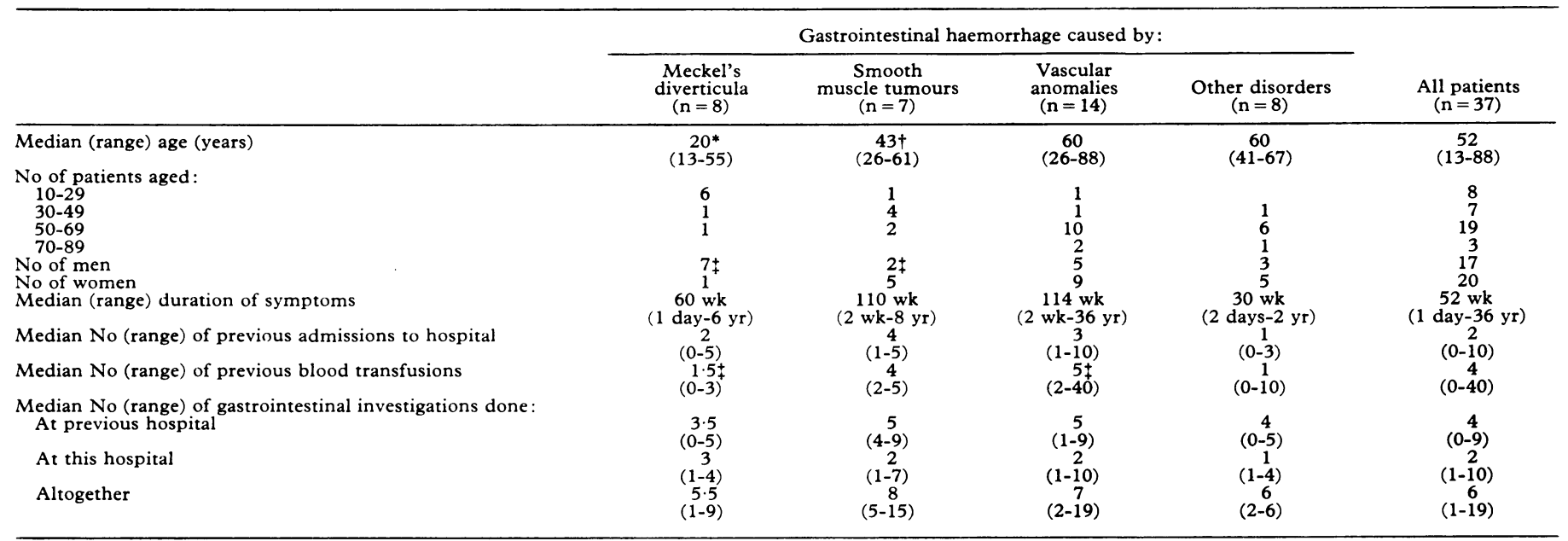

* Significantly younger than patients in all other groups $(p<0.01)$.

+ Significantly younger than patients with vascular anomalies or other disorders $(p<0.05)$.
+ Difference between groups significant $(p<0.05)$.

and autologous red cells labelled with ${ }^{9{ }^{9 m}} \mathrm{Tc}$ may be used to measure obscure gastrointestinal haemorrhage and localise its origin. ${ }^{13}{ }^{14}$ Although these techniques have some advantages over angiography, we reserve them for the most difficult of our patients-usually those who have rebled-and our experience with them is limited. Barium studies of the small bowel gave a low yield in our series, but the increased use of small-bowel enemas may increase diagnostic accuracy. ${ }^{10}$ Angiography or ${ }^{8{ }^{\mathrm{m}} \mathrm{Tc}}$ sulphur colloid scanning during haemorrhage would probably show the site of bleeding in over $90 \%$ of patients with obscure gastrointestinal haemorrhage. ${ }^{213}$ Small-bowel haemorrhage, however, is often clinically evident only after it has stopped, and these investigations are not always available at short notice.

Haemorrhage is the most common presenting feature of Meckel's diverticula, ${ }^{15}$ smooth muscle tumours, ${ }^{16}{ }^{17}$ and vascular anomalies of the small bowel. ${ }^{18-22}$ Men are more likely than women to haemorrhage from a Meckel's diverticulum, ${ }^{15}$ as was seen in this series, but our high proportion of female patients with smooth muscle tumours has not been found in other studies of larger numbers. ${ }^{1617}$ The high incidence of angiographic identification of smooth muscle tumours $(86 \%)$ contrasts with the low incidence for barium follow through examination and the low preoperative diagnostic incidence in previous series ${ }^{16}$ The proximal site of all seven smooth muscle tumours was significantly different $(p<0.05)$ from that in the series of River et al, ${ }^{16}$ suggesting that proximal tumours present more commonly with recurrent haemorrhage whereas distal tumours obstruct. The absence of vascular lesions on pathological examination in six of the patients who underwent resection of the small bowel did not preclude their existence as they may be difficult to show histologically. ${ }^{523}$

In conclusion, we suggest that early and careful laparotomy is appropriate for patients aged under 50 who present with obscure gastrointestinal haemorrhage as almost all these patients have a surgically identifiable lesion. In patients aged over 50 who present in this way, however, there is a high incidence of colonic angiodysplasia, ${ }^{2}$ and this study shows that these patients may also be bleeding from macroscopically unidentifiable lesions of the small bowel. In patients aged over 50 we therefore recommend that, before the patient undergoes exploratory laparotomy, selective visceral angiography is done by a radiologist who is experienced in the technique and its interpretation.

We thank Dr H J F Hodgson and Dr V S Chadwick, who were responsible for the initial management of some of these patients; $\mathrm{Dr}$ J P Lavender, who did the radioisotope scanning; and Mrs I Fisher, who prepared the report.

\section{References}

1 Spiller RC, Parkins RA. Recurrent gastrointestinal bleeding of obscure origin: report of 17 cases and a guide to logical management. Br $\mathcal{F}$ Surg 1983;70:489-93.

2 Allison DJ, Hemingway AP, Cunningham DA. Angiography in gastrointestinal bleeding. Lancet $1982 ; \mathrm{ii}: 30-3$.

${ }^{3}$ Spechler SJ, Schimmel EM. Gastrointestinal tract bleeding of unknown origin. Arch Intern Med 1982;142:236-40.

4 Allison DJ, Hemingway AP. Angiodysplasia: does old age begin at nineteen ? Lancet 1981 ;ii:979-80.

${ }^{5}$ Boley SJ, Brandt LJ. Colonic ectasias and lower intestinal bleeding. Hosp Pract 1982;17:137-44.

${ }^{6}$ Hines JR, Stryker SJ, Neiman HL, et al. Intraoperative angiography in intestinal angiodysplasia. Surg Gynecol Obstet 1981;152:453-60.

${ }^{7}$ Fazio VW, Zelas P, Weakley FL. Intraoperative angiography and the localisation of bleeding from the small intestine. Surg Gynecol Obstet $1980 ; 151: 637-40$.

8 Athanasoulis CA, Moncure AC, Greenfield AJ, Ryan JA, Dobson TF. Intraoperative localisation of small bowel bleeding sites with combined use of angiographic methods and methylene blue injection. Surgery $1980 ; 87: 77-84$.

${ }^{9}$ Hemingway AP, Allison DJ. Angiodysplasia and Meckel's diverticulum: a congenital association ? Br F Surg 1982;69:493-6.

10 Bartram CI, Amess JA. The diagnosis of Meckel's diverticulum by small bowel enema in the investigation of obscure intestinal bleeding. $\mathrm{Br} \mathcal{J}$ Surg $1980 ; 67: 417-8$.

11 Petrokubi RJ, Baum S, Rohrer GV. Cimetidine administration resulting in improved pertechnetate imaging of Meckel's diverticulum. Clin Nucl Med 1980;3:385-8.

12 Treves S, Grand RJ, Eraklis AJ. Pentagastrin stimulation of technetium ${ }^{99} \mathrm{~m}$ uptake by ectopic gastric mucosa in a Meckel's diverticulum. Radiology 1978;128:711-2.

${ }^{13}$ Baum S. Angiography and the gastrointestinal bleeder. Radiology $1982 ; 143$ : 569-72.

14 Heyman S, Sacks B, Khettry J, Steer ML. Localisation of bleeding small intestinal lesions using scanning techniques. Surgery 1979;85:372-6.

15 Williams RS. Management of Meckel's divertulum. Br F Surg 1981;68: 477-80.

${ }^{16}$ River L, Silverstein J, Tope JW. Benign neoplasms of the small intestine. Int Abstr Surg 1956;102:1-38. (See Surg Gynecol Obstet January 1956.)

17 Olson JO, Dockerty MB, Gray HK. Benign tumours of the small bowel. Ann Surg 1951;134:195-204.

18 Gentry RW, Dockerty MB, Clagett OT. Vascular malformations and vascular tumours of the gastrointestinal tract. Int Abstr Surg 1949;88: 281-323. (See Surg Gynecol Obstet April 1949.)

19 Hansen PS. Hemangioma of the small intestine. Am F Clin Pathol 1948;18: 14-42.

20 Shepherd JA. Angiomatous conditions of the gastrointestinal tract. $B r \mathcal{F}$ Surg 1953;40:409-21.

21 People JB, Kartha R, Sharif S. Multiple phlebectasia of the small intestine. Am Surg 1981;47:373-6.

${ }_{22}$ Morson BC, Dawson IMP. Developmental abnormalities. In: Gastrointestinal pathology. 2nd ed. Oxford: Blackwell Scientific Publications, 1979:254-6.

${ }^{23}$ Anonymous. Angiodysplasia [Editorial]. Lancet 1981 ;ii:1086-7.

(Accepted 28 February 1984) 